International Journal of Current Advanced Research

ISSN: O: 2319-6475, ISSN: P: 2319 - 6505, Impact Factor: SJIF: 5.995

Available Online at www.journalijcar.org

Volume 6; Issue 3; March 2017; Page No. 2711-2712

DOI: http://dx.doi.org/10.24327/ijcar.2017.2712.0084

CASE REPORT

\title{
PREVALENCE OF HEART DISEASE IN MEN AND WOMEN-INDIAN POPULATION
}

\author{
Nancy Selva Mary.V and Thenmozhi M.S
}

Saveetha Dental College and Hospital, Chennai - 600007

\section{A R T I C L E I N F O}

Article History:

Received $10^{\text {th }}$ December, 2016

Received in revised form $16^{\text {th }}$ January, 2017

Accepted $14^{\text {th }}$ February, 2017

Published online $28^{\text {th }}$ March, 2017

\begin{abstract}
A B S T R A C T
Aim: To do a comparative study in men and women in the prevalence of heart disease Materials and Methods: The study involved around 150 people and 2 questions about various heart problems and knowledge bout health in men and women heart disease Result: The age adjusted heart disease death lower for women than men throughout he study period
\end{abstract}

Copyright $@ 2017$ Nancy Selva Mary.V. This is an open access article distributed under the Creative Commons Attribution License, which permits unrestricted use, distribution, and reproduction in any medium, provided the original work is properly cited.

\section{INTRODUCTION}

Heart Disease is a major cause of mortality and morbidity all over the world. The prevalence and mortality due to heart disease is declining is developed the same cannot be held true for developing countries. There has been an alarming increase over the part two decades in the prevalence of heart disease mortality in India and other South Asian Countries.

India is going through an epidemiologic transition whereby the burden of communicable diseases have declined slowly, but that of non-communicable diseases has risen rapidly, thus leading to a dual burden. There has been a 4 fold rise of Heart disease prevalence in India during the past 40 years. Current estimates from epidemiologic studies from various parts of the country indicate a prevalence of heart disease to be between $7 \%$ and $13 \%$ in urban $3-5$ and $2 \%$ and $7 \%$ in rural 67 populations.

The burgeoning burden of heart disease in India can be explained by the alarming rise in the prevalence of coronary risk factors like diabetes, hypertension, atherogenic dyslipidemia, smoking, central obesity and physical inactivity. Rapid urbanization and change in lifestyle that occurred during the past two decades have led to the growing burden of coronary risk factors in India. Previous studies conducted in migrant Indians were misinterpreted to indicate that conventional risk factors do not account for the high prevalence and premature occurrence of heart disease among Indians.

*Corresponding author: Nancy Selva Mary V

Saveetha Dental College and Hospital, Chennai - 600007

\section{MATEIALS AND METHODS}

The study involved around 150 people randomly selected from different parts of Chennai. The questionnaire includes 20 question that data from the questionnaire were extracted and analysed and knowledge about health in men and women. The study period was conducted for two months. The result was finally analysed after questionnaire interview

\section{RESULTS}

Generally the result in the study will be different when compared to the men and women. According to the World Health Organisation (WHO) in 2005 Cardiovasular disease caused 17.5 million of the 58 millions deaths that occurred world wide Epidemiology studies shows that there are at present over 30 million cases of heart disease in this country.

The Result shows that the age adjusted heart disease death lower for women than men throughout the study period. Therefore the age of death due to heart disease during this time 74 years for men and 81 years for women. This means that the average men died more than seven years earlier from heart disease than women although most heart disease occurred to person over 75 in both sexes. The proportion of deaths that occurred to people under 75 was larger for male.

\section{DISCUSSION}

The highest prevalence of heart disease among Indian population. Heart disease is very common in developed countries. Heart disease was recently dethroned as the leading cause of death over the world. It still represents a major hurdle to people health.Heart disease was the number one 
leading cause of death for both men and women during all years. The age-adjusted heart diseases death rate was lower for women than men throughout the study period both the men and women experienced statically significant rate decreases.

\section{CONCLUSION}

The study observed that the prevalence of heart disease in Men and Women. Low education level was associated with increased risk of heart diseases would under women had a poorer physical and mental health with more Physical Limitations prior to their heart attack than similar aged men with heart attacks. The Women were also more likely than men to have other condition associated with heart diseases.

\section{Reference}

1. World health Organisation; Genera; 2005 preventing chronic diseases: A vital Investment.

2. Prevalence of Coronary heart disease-U10. Morb Mortal Wkly Rep (MMWR) 2011; 60(40); 1377-138 (Pubmed)

3. R.Gupta VP. Preavalance of coronary heart disease and risk factors

4. Fetal gowth, socialfactors and circulatory isease.act univ upsliensis 1997;698:7-60

5. Mozaffarian d, roger vl, et al. heart disease and strok statistics-214 update a repet fom the American heart association. circulation 2014

6. Friden tr, erwick dm the million hearts preventing heart attacks and strokes

7. Vesper hw, kuiper hc, mirel lb/Johnson cl,pirklj1.lvelso plasmatrans fatty acids in hispanc hitw adults in the united states

8. Lioyd-jones defining and setting goals for cardiovascular he

Please cite this article in press as:

Nancy Selva Mary.V and Thenmozhi M.S (2017), Prevalence Of Heart Disease In Men And Women-Indian Population, International Journal of Current Advanced Research, 6(3), pp. 2711-2712.

http://dx.doi.org/10.24327/ijcar.2017. 2712.0084 